\title{
Crisis Neoliberal, Políticas Del Desconcierto y Autoritarismos Populistas
}

Gonçal Mayos ${ }^{1}$

Resumen: En el 2008 la crisis financiera mundial provoca la quiebra de instituciones tan emblemáticas como la compañía Blackstone o el famoso banco de inversión Lehman Brothers. Fue necesario el rescate con costes enormes de prácticamente todo el sector bancario y de seguros norteamericano y europeo. En medio de esta gran crisis surgieron muchas propuestas de "reforma del capitalismo" neoliberal. Se produce, además, un enorme desconcierto político asociado a la mala resolución de las crisis económicas y a los malestares acumulados por gran parte de la

\footnotetext{
1 Profesor titular de filosofía de la Universidad de Barcelona y coordinador del doctorado Ciudadanía y Derechos Humanos, Ética y Política. Es director de los grupos de investigación GIRCHE (Grupo Internacional de Investigación Cultura, Historia y Estado') y OPEN-PHI (Open Network for Postdisciplinarity and Macrophilosophy) y consultor de Humanidades de la UOC. Es miembro del Seminario de Filosofía Política UB y del proyecto de investigación "CONTROL SOCIAL: POLITICA, FILOSOFIA Y NUEVAS CULTURAS” (PGC2018-101145-BI00) del Ministerio de Ciencia, Innovación y Universidades. Dirige las webs académicas:

http://www.ub.edu/histofilosofia/gmayos/

http://goncalmayossolsona.blogspot.com/
}

B CLIVATGE, número 8

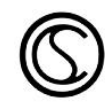


población que se siente menospreciada y abandonada por las instituciones, provocando desafección y anomía social. En medio de todo esto, muchas de las alternativas propuestas por los movimientos populistas son políticas instituyentes y destituyentes que nadie sabe qué consecuencias tendrán a largo plazo. Este va a ser el eje que guía la reflexión y el análisis de este artículo.

Palabras clave: crisis neoliberal, populismos

Abstract: In 2008, the global financial crisis had such emblematic institutions as Blackstone or the popular investment bank Lehman Brothers filing for bankruptcy. The virtual totality of the American and European banking and insurance sectors had to be rescued at enormous expense. In the middle of this great crisis, we saw the emergences of many proposals to "reform neoliberal capitalism". Besides this, there was enormous political confusion, linked to the inadequate resolution of economic crises and an accumulated feeling of unease experienced by large parts of the populations, who felt demeaned and abandoned by the governing institutions, which, in turn, caused political disaffection and social anomy. Amid all this, many of the alternatives put forward by populist movements were about establishing new institutions and ending present ones, which no one knows what consequences will have in the long term. This will be the axis around which our reflexion and analysis will revolve in this article.

Keywords: neoliberal crisis, populisms

B CLiVATGE, número 8

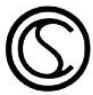


Resumen: L'any 2008, la crisi financera mundial provoca la fallida d'institucions tan emblemàtiques com ara la companyia Blackstone o el famós banc d'inversió Lehman Brothers. Va ser necessari el rescat, amb costos enormes, de la pràctica totalitat dels sectors bancari i d'assegurances nord-americà i europeu. Enmig d'aquesta gran crisi van sorgir moltes propostes de "reforma del capitalisme" neoliberal. Es va produir, a més a més, un enorme desconcert polític associat a la mala resolució de les crisis econòmiques i al malestar acumulat per una gran part de la població, que es va sentir menyspreada i abandonada per les institucions, la qual cosa va provocar desafecció i anomia social. Entremig de tot això, moltes de les alternatives proposades pels moviments populistes són polítiques instituents o destituents que ningú sap quines conseqüències tindran a llarg termini. Aquest serà l'eix que servirà de guia a la reflexió i anàlisi d'aquest article.

Paraules clau: crisi neoliberal, populismes

\section{Crisis en serie y desconcierto resultante}

Introduzcamos primero un conciso relato del marco general que nos lleva hasta hoy. La desregularización económico-financiera neoliberal, el especulativo "capitalismo de casino", el consenso de Washington y la era de la austeridad están en la base en una ya larga serie de crisis económicas enlazadas. El primer aviso fue el estallido de la burbuja.com que afecta a las empresas tecnológicas digitales y vinculadas a Internet a partir de Marzo del 2000 y sólo

B CLIVATGE, número 8

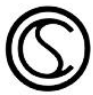


se recupera con más prudencia a partir de finales del 2003. Ahora bien, a partir de la gran crisis hipotecaria "subprime" del 2007 se generala la desconfianza en el crédito produciendo quizás la serie negativa más grave y generalizada desde el Crac de 1929.

En el 2008 la crisis financiera mundial provoca la quiebra de instituciones tan emblemáticas como la compañía Blackstone o el famoso banco de inversión Lehman Brothers. Sobre todo fue necesario el rescate con costes enormes de prácticamente todo el sector bancario y de seguros norteamericano y europeo. Al final, nadie pudo o no quiso evitar la cruel dinámica de privatizar los éxitos y beneficios, pero nacionalizar y cargar al erario público los fracasos y pérdidas generados -precisamente- por la avaricia en la búsqueda a toda costa de aquellos beneficios privados.

En medio de esta gran crisis surgieron muchas propuestas de "reforma del capitalismo" neoliberal en expresión del presidente francés Nicolás Sarkozy. En concreto se trataba de revertir la principal causa de esa serie de burbujas especulativas y de sus consecuentes crisis que fue la eliminación de los controles y regulaciones creados de resultas del Crac de 1929 para evitar su futura reedición. Ahora bien, cuando el pánico económico cesó y la inyección de dinero público salvó las empresas y la economía, se olvidaron acelerada e incomprensiblemente las propuestas de reforma en profundidad.

Se continuó e incluso profundizó en un proceso de larga duración neoliberal que había comenzado -recordémoslo- como suavización del keynesianismo posterior a la Segunda Guerra Mundial ante la ralentización del crecimiento económico a partir de la crisis del

B CLIVATGE, número 8

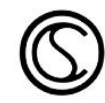


petroleo de 1973. Ese mismo año se inició el "experimento" económico chileno postAllende inspirado en la Escuela de Chicago de Hayek y Friedmann que, a pesar de las penurias sufridas por la población, fue considerado un éxito.

Ello impulsó las políticas neoliberales de desmontaje del Estado del bienestar y de desregularización económico-financiera llevadas a cabo por los presidentes de la Gran Bretaña y los Estados Unidos, Margaret Thatcher y Ronald Reagan. En el contexto social, económico y político favorable a Occidente por la caída del "socialismo real" de la URSS, pero también por la más callada y pragmática evolución económica de la China de Deng Xiaoping, también fueron consideradas un éxito. Incluso y a pesar de las muchas críticas, se hicieron de ellas una política generalizada y radical que se globalizó a través del llamado "Consenso e Washington" en los años 1990 (Williamson).

Como hemos sintetizado, todo ello provocó distintas "burbujas" especulativas que llevaron a la Gran crisis 2007-2009 que ha iniciado nuestro relato y -como consecuencia- a las "políticas del desconcierto" (Mayos, 2020 y 2018b) y a dos oleadas populistas que analizaremos más adelante-. El desconcierto político está asociado a la mala resolución de las crisis económicas y a los malestares acumulados por gran parte de la población que se siente menospreciada y abandonada por las instituciones, provocando desafección y anomía social. A inicios de la segunda década del siglo XXI, capas importantes de la sociedad viven momentos de angustia y desorientación. Están faltos de guías y de referentes creíbles, pues tampoco se ha actualizado adecuadamente el concierto teórico-

B CLIVATGE, número 8

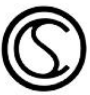


práctico de gobernanza global del "Consenso de Washington". Además, éste es profundamente atacado sobre todo por los populismos de izquierda y derecha, mientras que los partidos más tradicionales no consiguen mostrar el valor de mantenerlo y parecen superados por los acontecimientos.

Ahora bien, muchas de las alternativas propuestas por los movimientos populistas son políticas instituyentes y destituyentes que nadie sabe qué consecuencias tendrán a largo plazo. Por otra parte, el contexto social y laboral incorpora nuevos interrogantes. A la fuerte competencia internacional económico-tecnológica por la turboglobalización se suma la llegada de una nueva revolución basada en la inteligencia artificial y la robótica que amenaza generar un paro estructural a nivel mundial totalmente inédito hasta ahora (Rifkin: 1996; Mason, 2016). Por ello se han desarrollado acuciantes debates sobre posibles fórmulas de "renta básica universal”, pero sin llegar al más mínimo consenso.

Neoliberalismo y desconcierto como marco de los populismos Lo explicado en el apartado anterior ha convertido en obsoleto el "concierto" económico, social, político y cosmovisional que dificultosamente se había construido en los últimos 30 años. Al gran eje de la política tradicional basado en la mayor o menor redistribución económica que enlazaba con la distinción "de clase" izquierda-derecha, se le sumó el eje de mayor o menor reconocimiento e inclusión de cuestiones ecológicas; de las diferencias de género, étnicas, raciales y culturales; y de las distintas minorías sociales.

B CLIVATGE, número 8

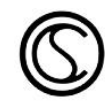


Pero ambos ejes se han mostrado poco eficaces para estructurar ideológicamente a los nuevos populismos que hacen gala de no ser "ni de derechas ni de izquierdas", además de atacar violentamente muchos de los consensos sociales alcanzados trabajosamente sobre el cambio climático, la ecología, los géneros, los colectivos LGT, las minorías, las políticas positivas, etc. Ello ha ampliado incluso el desconcierto que se experimentó en los años 1960, cuando se incorporaron con fuerza por primera vez las politizaciones del reconocimiento. Entonces los partidos -tanto de derechas como de izquierdas- basados entonces casi exclusivamente en el eje redistributivo quedaron desconcertados ante la eclosión de los nuevos movimientos sociales. Éstos coincidían en ir más allá de la estricta dualidad de clase y encarar conflictos complejos que hasta entonces se tendían a negligir entre incluidos-excluidos, establishment-disidencia/contracultura, mayorías-minorías...

La Gran recesión post2007, la austeridad, la turboglobalización y los cambios tecnológicos han provocado un desconcierto aún superior, sobre todo por un inquietante contexto económico que en los 1960 no se daba en Occidente. Especialmente los populismos han detectado y usado políticamente los malestares fruto de la creciente escisión entre los vencedores y perdedores por esos grandes cambios. Como dice el Informe CIDOB 'El món el 2019', han introducido divisiones internas y "muros invisibles" que a veces son más rotundos e impactantes que los tradicionales entre las fronteras nacionales. Por eso no tiene que extrañar que tanto populismos de derecha como de izquierda reclamen protecciones

B ClivatGE, número 8

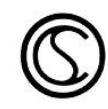


nacionales, aislacionismos, discriminación xenofóbica y prácticas de guerra comercial.

De ahí proviene gran parte del predicamento actual de autoritarismos o iliberalismos a lo Putin, Xi Jinping, Trump, Le Pen, Orbán, Bolsonaro, Erdogan... Muchas veces se añora el viejo Estadonación sintiendo que ha perdido agencia y capacidad de proteger la población sin que -en cambio- emerja una clara, ordenada y protectora gobernanza que los sustituya. Todo parece indicar que en la salida de la Gran Bretaña de la Unión Europea hay tanto la nostalgia del antiguo imperio británico como -y quizás más- que la gobernanza europea no consigue inspirar similar confianza en la gente.

Las "políticas del desconcierto" y los populismos son pues en gran medida resultado de falta de una nueva gobernanza preparada para la turboglobalización y de la ineficacia de las instituciones democráticas actuales. Nacen pues de tensiones sociales, económicas y políticas provocadas por sobre todo por:

- la competencia turboglobalizada que fomenta las deslocalizaciones industriales, la movilidad y poca tributación de los capitales internacionales, $y$ las migraciones $y$ el multiculturalismo de las sociedades.

- los "fenómenos-inter" que van integrando crecientes regiones mundiales a efectos económicos (pero no exclusivamente), sin conseguir sustituir en el imaginario, pero también en la vida cotidiana de las personas a los viejos "Estados-nación" que tradicionalmente eran capaces de unas fronteras estancas que hoy

B CLIVATGE, número 8

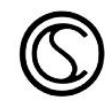


han devenido imposibles (como muestra la expansión del virus Covid-19).

- la dificultad de equilibrar y satisfacer las tensiones opuestas entre la globalización, la democracia política y la soberanía nacional (Rodrik, 2012).

Las consecuencias de la depresión post2007 han provocado un gran estrés en las economías, pero también en las sociedades y estructuras políticas. El anterior sistema de partidos y de instituciones no ha gestionado bien esta larga crisis (Hopkin \& Blyth, 2018) que ha empobrecido gran parte de la población. Ello ofrece una oportunidad histórica a nuevos movimientos sociales y liderazgos políticos que han irrumpido con fuerza generando respuestas crecientemente iliberales (Rodrik, 2012 y 2018) y fuera del marco tradicional. Ahora bien, se trata de una oportunidad política que manifiesta posturas ideológicas muy distintas.

Además, como remarca Laclau (2005), la "razón populista" puede ser instrumentalizada por cualquier contenido ideológico concreto, tanto de izquierdas (el propio de Laclau) como de derechas. Pues si se trata de obtener el poder mediante elecciones (y no por un golpe de Estado) es vital generar una alianza mayoritaria que aúne los distintos malestares y politizaciones en un marco "popular" común. Laclau destaca la importancia de usar para ello "conceptos flotantes" (la "libertad" es uno habitual desde hace muchas décadas) que permitan movilizar al máximo las multitudes. Ahora bien, esa estrategia o mecanismo político puede llevarse a cabo desde ideologías opuestas.

B CLIVATGE, número 8

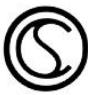


Aunque ya habían antecedentes que muchas veces se habían menospreciado, el populismo contemporáneo explota sobre todo después de las crisis enlazadas entre 2007-2009. Primero se movilizaron sectores críticos de izquierda entre 2011 y 2014 por ejemplo en el 15M, en las Primaveras árabes, Occupy Wall Street, en las manifestaciones brasileñas del 2013 o en las reacciones frente a la deuda griega. Pero luego -entre 2016 y 2019- la movilización se centró en sectores más a la derecha, por ejemplo, alrededor de Steve Bannon y Trump, la salida de la Gran Bretaña de la Unión Europea, el voto en contra del pacto de pacificación en Colombia, la deriva iliberal de la presidencia de Viktor Orbán en Hungría o la eclosión de Cs y Vox en España y de Matteo Salvini en Italia.

Ello concentró la atención en el libro del 2005 On Populist Reason del politólogo postmarxista argentino profesor en la Universidad de Essex, Ernesto Laclau. El término "populismo" parecía describir esos nuevos movimientos y anticipar las posteriores "políticas del desconcierto" (Mayos, 2020) que rompían los consensos y prácticas políticas tradicionales. Ahora bien, la desorientación de los analistas era prácticamente comparable a la de los votantes, mientras aumentaba la virulencia en los conflictos y luchas políticas, mostrando que la sociedad surgida de la gran crisis económica estaba mucho más profundamente escindida de lo que nadie había sospechado. Brotaban en ella poderosas fuerzas antagonizantes que -además- eran amplificadas por nuevas tecnologías con gran impacto político, como se vio en resultados electorales inesperados como la victoria presidencial de Donald 
Trump sobre Hillary Clinton o el resultado del referéndum por el Bréxit.

Habían aparecido nuevas y profundas tensiones en los Estados y gobernanzas democráticos, que no desaparecerían fácilmente, como algunos insistían en creer. Pero faltaba todavía una teoría mínimamente completa que las explicará y que -sobre todopermitiera reconducir esas profundas tensiones político-sociales.

\section{¿Cómo en los años 1930 o en el peronismo?}

La atención preocupada se dirigía a otros momentos parecidos de "políticas del desconcierto" como la Europa de los años 1930. Pues era una sociedad marcada también por la crisis económica y enfrentamientos radicales entre regímenes fascistas y comunistas que, ayudados por la inoperancia de las democracias occidentales, imponían una agenda cada vez más totalitaria, menospreciadora de las instituciones liberales y que llevó a la Segunda Guerra Mundial. Ahora bien, los intentos de analizar detalladamente en términos de fascismo y comunismo a las "políticas del desconcierto" posteriores a la serie de crisis económicas 2007-2009, no conseguían captar las complejidades de la segunda década del siglo XXI. Incluso analistas matizados como el liberal José María Lassalle (2017: 26) exageran cuando describen el populismo como una especie de totalitarismo como en los 1930 pero de baja intensidad, debido a las características de la sociedad postmoderna.

Tanto los fascismos como los comunismos de los años 1930 tendían a identificar democracia e instituciones liberales. De tal manera que proponían revoluciones -ciertamente de signo contrario- que

B CLIVATGE, número 8

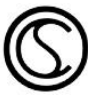


deberían superar totalmente a ambas. En cambio las "políticas del desconcierto" de la segunda década del siglo XXI, desafían ciertamente la gobernanza liberal, pero al menos nominalmente se respeta el ideal democrático y las elecciones libres y multipartidistas.

Sorprendentemente y a pesar de algunos exabruptos muy inquietantes, los nuevos movimientos políticos desafiadores y populistas se mantienen básicamente dentro de los marcos electorales heredados. Además así como veremos muchos de sus votantes, que aplauden o al menos aceptan sus derivas iliberales, no manifiestan una crítica semejante al ideal democrático. Eso no solía pasar en los años 1930 ni por parte de los fascismos ni por parte del comunismo y nos parece una diferencia a tener muy en cuenta, pues hace que la evolución actual de las políticas "del desconcierto" pueda ser muy diferente que en el pasado.

Ciertamente gran parte de la población transacciona hoy angustiada- valores de libertad y algunos derechos civiles a cambio de valores de seguridad, de liderazgos fuertes y de promesas de excluir sectores que ven como competidores (como los inmigrantes). Pero los derechos humanos y las libertades civiles son -con la democracia- de los pocos ideales que mantienen hoy un consenso muy mayoritario. Repetimos que eso no pasaba en los años 1930.

$\mathrm{Al}$ respecto nos parece significativo que los ataques directos de la ultraderecha a conquistas feministas, de libertad y igualdad de género, eutanasia, aborto y divorcio no han conseguido el apoyo ampliamente mayoritario de la ciudadanía que esperaban.

B CLIVATGE, número 8

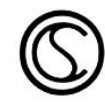


Acciones como Me Too, "el violador eres tú" y en contra de la violencia de género se mantienen muy potentes, mayoritarias y han obligado a redefinir estrategias muy agresivas de la extrema derecha. Ya Vallespín \& Martínez-Bascuñán (2017: 14) apuntaron una cierta inflexión en el crecimiento de los populismos de derecha por reacción de parte de sus votantes ante su agresivo crecimiento. Pudo percibirse ya el 2017 en les elecciones holandesas y presidenciales francesas donde Macron era a la vez renovador, pero "representante de la política sistémica".

Lamentablemente los esfuerzos humanitarios en favor y en contra de los refugiados e inmigrantes no tienen un soporte tan mayoritario y por todas partes se levantan muros separadores. A pesar de la crisis fronteriza en Grecia provocada por el presidente turco Recep Erdogan a inicios del 2020, se mantienen a un alto nivel los valores de acogida en gran parte de la ciudadanía. Recordemos por ejemplo que Matteo Salvini tuvo que dimitir y está imputado judicialmente, mientras que la agresividad de Vox ha tenido que suavizarse recientemente de forma similar a como lo han ido haciendo Ciudadanos y el Partido Popular en España.

Hemos apuntado solo unos ejemplos muy debatidos que marcan una gran diferencia entre las décadas de 1930 y de 2010. Quizás puede haber una agenda oculta parecida entre grupos radicales, pero la táctica pública, reivindicativa y electoral es mucho más suave si bien tampoco libre de riesgos. El retorno al fascismo y totalitarismo de los años 1930 no se está confirmando por el momento.

B CLiVATGE, número 8

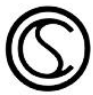


En cambio, como apuntaba claramente Laclau (2005), reclaman Vallespín y Martínez-Bascuñán (2017) y sintetizan Rivero, Zarzalejos y Palacio (2017) es importante superar el eurocentrismo y analizar los populismos latinoamericanos y del resto del mundo. Pues muchas veces introdujeron novedades que se han perpetuado en los actuales. Es el caso -por ejemplo- del modelo populista del general Juan Domingo Perón y su mediática y movilizadora esposa Eva Duarte "Evita" en su presidencia de 194655 , que tendría una significativa reiteración en la nueva victoria presidencial de 1973 que -por la muerte de Perón- llevaría al poder entre 1974-1976 a su segunda esposa María Estela Martínez "Isabelita". También sería interesante profundizar en el populismo presente en el Brasil de Getulio Vargas, período cuya historia ha analizado muy bien el profesor Alexandre Walmott en su segunda tesis doctoral todavía en prensa.

En las políticas del desconcierto actuales, los ideales democráticos, el voto popular y los derechos humanos y civiles mantienen en general una gran vigencia como "campo de juego" político básico y con mucho soporte ciudadano. No son desafiados al mismo nivel que en los años 1930 y como los "checks and balances" liberales. Pues éstos son acusados de perpetuar la inoperancia de las instituciones tradicionales frente a la muy acuciante y dolorosa crisis económica, social y política.

Actitudes autoritarias y autocráticas -que se perciben en muchos de los líderes y movimientos populistas- son consentidos e incluso celebrados por partes considerables de la población como una "necesidad" e intento "sincero" de no demorar las reformas y

B CLIVATGE, número 8

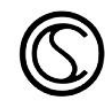


decisiones. Ello es sin duda clave para entender la popularidad persistente de por ejemplo Donald Trump, que está superando notables reveses nacionales -impeachment, dimisiones de miembros importantes de su equipo-e internacionales -fracasos militares y retrasos en desmilitarizaciones prometidas-.

\section{Populismo "del desconcierto" y su capacidad de movilización emotiva}

Quizás todo cambiará pronto, pero por el momento tanto los movimientos populistas más de derecha y más de izquierda coinciden en algunos puntos significativos. Como veremos algunos de ellos son de gran eficacia en las sociedades avanzadas, por lo que esas prácticas de los populismos les están dando significativas ventajas dentro de la "ventana de oportunidad" que representa para ellos las actuales "políticas del desconcierto".

Destacamos en primer lugar que hacen gala de incluir en la agenda política (veremos si la inclusión será real y permanente) los malestares e intereses de partes de la población que se consideran a sí mismas olvidadas por las políticas y el sistema de partidos hegemónicos antes, durante y después de las duras crisis económicas. Además, los populismos evitan el elitismo comunicativo de los partidos tradicionales sumando -a argumentaciones frías, racionales y de cálculo instrumentalmuchas apelaciones emotivas y pasionales. Esto último es un aspecto muy destacado y que, a veces, se presenta como un rasgo anticuado cuando enlaza con las actuales teorías de la persuasión

B CLIVATGE, número 8

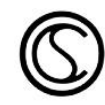


política y de la naturaleza humana (por ejemplo, Storytelling, Lakoff, o Damasio).

Ernesto Laclau y Chantal Mouffe habían criticado en Hegemony and Socialist Strategy (1985) el sistema ideológico marxista del cual ellos mismos partían. Así lo incluían en su denuncia de la creciente imposición de una gobernanza neoliberal. Desde ese libro germinal abogaban por una profunda renovación de la política que actualizaba la función de los partidos, las prácticas y los discursos políticos. Chantal Mouffe (2018) asocia el populismo izquierdista con el ideal de "democracia radical" y la polémica construcción democrática del "pueblo". Recordemos que coincide plenamente con Laclau (2005) en que no puede darse por supuesta ni la movilización política eficaz del "pueblo" ni la cohesión de la muy distintas demandas que se pueden presentar en su seno; al contrario, eso es algo que se construye precisamente con la acción política.

Mouffe considera que una "democracia radical" puede equilibrar la jerarquización vertical de los malestares y reivindicaciones con el empoderamiento autónomo y horizontal de los distintos grupos implicados. Así se evitaría tanto la anarquía caótica como el despotismo tecnocrático paternalista; y la democracia radical populista podría ejercer un saludable poder constituyente que superara los tradicionales déficits democráticos de la izquierda revolucionaria. Ahora bien, también obvia los tradicionales equilibrios liberales y la estricta división de poderes de Montesquieu, con lo cual parece que las tendencias iliberales son presentes tanto en los populismos de izquierda como de derecha.

B CLIVATGE, número 8

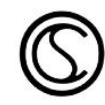


Por otra parte, las estrategias movilizadoras emotivistas no son en absoluto patrimonio de las izquierdas y los populismos de derechas están demostrando una enorme capacidad para usarlas. Forman parte de la decisiva influencia en los respectivos presidentes de auténticas potencias mundiales como Vladimir Putin, Jair Bolsonaro y Donald Trump de sus intelectuales "de cabecera" Aleksandr Duguin, Olavo de Carvalho y Steve Bannon. Después de dejar su cargo en la Casa Blanca, Bannon se está convirtiendo en el más importante impulsor internacional del populismo de ultradecha asesorando muchos partidos en esa línea.

En gran medida gracias a consejeros como ellos, los movimientos populistas (a pesar de sus divergencias ideológicas e incluso peligrosos "inventos" políticos) están adaptándose ágilmente a las dificultades de las "políticas del reconocimiento", y superando a los partidos tradicionales que se muestran muy faltos de reflejos. Vallespín y Martínez-Bascuñán (2017: 15) incluso consideran contraproducentes muchas reacciones antipopulistas de los partidos tradicionales, pues son percibidas por muchos como elitistas, defendiendo el establishment a ultranza y "anti pueblo". Podemos constatar que las mencionadas características de los populismos han sido clave en casos concretos como -por ejemplola gran movilización del voto en favor de Donald Trump. La primera en detectarlo agudamente fue Arlie Russell Hochschild (2016) en su estudio de campo iniciado antes de las presidenciales pero confirmado poco después. Fue en ese magma social y mental, donde Trump consiguió fidelizar militantemente a poblaciones que ciertamente formaban parte del granero de votos que radicalizó al

B CLIVATGE, número 8

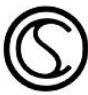


partido republicano, pero también a gente que había manifestado tentaciones absentistas o que -incluso- votaban en contra de los republicanos.

El cambio obtenido de actitud se percibe estadísticamente en grupos "lumpen" o descabalgados (rednecks, hillbillies o white trash), pero también grupos "wasp" (white, anglo-saxon and protestant) hasta hace poco "mainstream" de la llamada América profunda e incluso obreros del cinturón "del óxido", que ha sufrido una muy importante desindustrialización. En esos casos Hillary Clinton era percibida (más que el también demócrata Berni Sanders) como defensora de un frío, distante e indiferente establishment de Washington, al cual precisamente se enfrentaban Donald Trump y Sanders (por eso se percibió un inesperado traspaso de votos del segundo al primero).

Algo parecido pasa con la victoria de Le Pen en ciudades "proletarias" y que solían votar socialista como Marsella (Guilluy, 2015, documenta perfectamente las bases económicas de ese descontento) o de Vox en zonas de España más desafectas al régimen democrático de 1978 y que sienten añoranza del dictador Francisco Franco. Muchos votantes se han sentido interpelados e incluidos por la fuerza y proximidad emotiva del discurso populista, más que por los siempre vagos argumentos que han sido profusamente reiterados en las últimas décadas. Algo parecido creemos que está detrás de muchos votantes populares en favor de Jair Bolsonaro, que seguramente antes habían votado al Partido de los Trabajadores de Inácio Lula da Silva.

B CLIVATGE, número 8

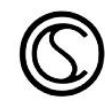


En todos los casos, el cambio de voto de mucha gente constata que se siente olvidada por el establishment político y damnificada por la pérdida de trabajo con las nuevas tecnologías, por la precariedad impulsada por el neoliberalismo y por las deslocalizaciones generadas por la turboglobalización (Mayos). Ronald Inglehart (2018) constata que desde la serie de crisis post2007 se ha manifestado en las "Encuestas Mundiales de Valores" un "reflujo autoritario" en gran parte de la población y que estaría asociado con el crecimiento de los populismos. Esa misma población, en cambio, siente que es interpelada, considerada y que puede ser incluida por los nuevos movimientos populistas. Otra cosa es, si lo será de forma suficiente y a largo plazo. Pero los populismos no solo roban votantes a los viejos partidos, sino que muchas veces atraen aquellos que habían pasado a la abstención por sentirse olvidados o muy poco reconocidos.

\section{Revolución posibilitista constituyente, opuesta al modelo "Octubre"}

Otro elemento transversalmente compartido por populismos de derecha e izquierda en las políticas del desconcierto, es aspirar a ejercer un significativo poder constituyente. Es decir, proclaman su voluntad de transformar profundamente al ejercicio concreto de la política, de superar los hábitos y formalidades políticos heredados, de subvertir las prácticas habituales y de revitalizar las instituciones ineficaces. Sus éxitos electorales se basan en que mucha gente ve la causa de sus malestares actuales en esas inercias políticas. Que se reforme efectivamente lo que llamamos "poder

B CLIVATGE, número 8

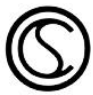


constituido" es -una vez más- otra cuestión. Pero el cambio de votos parece contemplar y apostar por esa posibilidad.

Como insiste Ernesto Laclau (2005), el populismo es una tendencia permanente en la política que aparece y se impone cuando fracasa ostensiblemente la política tradicional. Es una tendencia constituyente que se impone cuando una gran mayoría de la ciudadanía muestra su desafección con respecto a las élites hegemónicas y a las instituciones desgastadas (Vallespín y Martínez-Bascuñán 2017:26) como sucede hoy con la crisis post2008 i la imposición generalizada del pensamiento único neoliberal ${ }^{2}$. En tales casos, el populismo lidera un proceso "destituyente" de esas élites e instituciones, en favor de "instituir" otras de alternativas y así hacer frente a los nuevos retos históricopolíticos.

Ello nos lleva a otra característica de los populismos actuales y es que asumen un discurso a la vez revolucionario y posibilista. Pues en lugar de plantear una revolución completa de la sociedad y del modo de producción, se concentran en algún cambio que la gente percibe como urgente y muy relevante. Esta característica populista suele desconcertar a partidos asociados al marxismo; los cuales sufren las consecuencias de que, o bien sus propuestas revolucionarias han sido relegadas una y otra vez, o bien cuando se

\footnotetext{
${ }^{2}$ Com apunta Peter Sloterdijk (2005. En el mundo interior del capital. Para una teoría filosófica de la globalización), el capitalisme és un immens procés de desinhibició que és propens a la follia. Desconjunta la ment humana i la societat, generant violència, enfollint, desinhibint les pulsions i culminant el nihilisme predit per Nietzsche.
}

B CLIVATGE, número 8

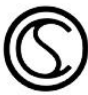


han pretendido llevar a la práctica no han cumplido con las expectativas o han sido pronto revertidas (por los mismos partidos o por un cambio de régimen más o menos forzado).

El resultado es que gran parte de la población que desea un cambio profundo e incluso revolucionario, se contenta hoy con propuestas no totales, pero que se perciben como significativas y factibles. Dentro de esas medidas percibidas como suficientemente "revolucionarias" y "constituyentes" suelen incluirse en primer lugar un cambio significativo de las élites gobernantes. Los populismos suelen ser alimentados por élites relativamente marginales al sistema que denuncian la inoperancia de las dominantes y proponen sustituirlas. Aunque puedan haber estado relativamente cerca de los poderes tradicionales, tanto Trump como Bolsonaro, Le Pen o Vox se presentan como enemigos acérrimos de éstos y dispuestos a substituirlos de manera espectacular.

Veremos cómo reaccionan esos grupos que esperan cambios radicales, si éstos se quedan en meramente cosméticos, si no tienen un gran impacto en sus vidas o si -como se dice- termina encumbrando a "los mismos perros con otros collares". Pero para entonces el sistema de partidos y probablemente muchas prácticas políticas habrán sufrido una decisiva transformación. La situación real de la gente podría no cambiar profundamente, pero sin duda lo harán las élites y supraestructuras institucionales. Por ello muy probablemente, las actuales "políticas del desconcierto" y los populismos habrán dado lugar a un nuevo régimen políticoinstitucional.

B CLIVATGE, número 8

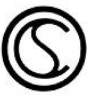




\section{Partido disciplinado versus movimiento y comunicación directa del líder}

Recordemos brevemente que el modelo revolucionario hegemónico fue durante décadas el bolchevique de Octubre del 2017. Era un movimiento político militar que aspiraba a la toma directa e inevitablemente violenta de los centros vitales del poder estatal: gobierno, ministerios, cuarteles, medios de comunicación, centros logísticos, grandes fábricas, etc. En cambio, el populismo de las políticas del desconcierto más bien utiliza estrategias no violentas, de conquistar el poder de forma indirecta, por ejemplo a través de controlar económicamente los medios, influir en el voto y conseguir lo que Antonio Gramsci llamaba una "hegemonía cultural" o un nuevo "sentido común".

En las revoluciones tradicionales el medio político principal era la creación de un disciplinado partido, bien estructurado con fiables cuadros ideologizados y militantes aguerridos. El tipo leninista de partido era el ideal para llevar a cabo un golpe de Estado y -en caso de éxito- gobernar desde el primer momento con mano de hierro a la sociedad e imponer el nuevo régimen.

Ahora bien, los populismos contemporáneos más bien nacen como movimientos amplios, poco coherentes y estructurados, y relativamente informales. Pueden manifestar una ideologización flexible, a veces extraída de corrientes religiosas independientes, como la llamada "Mayoría moral" que encumbró Ronald Reagan o el "evangelismo" que -recientemente- ha llevado a Jair Bolsonaro a la presidencia brasilera o ha expulsado Evo Morales de la presidencia de Bolivia.

B CLIVATGE, número 8

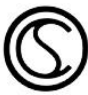


También se están generalizando estrategias sistemáticas e inéditas hasta ahora, por las cuales los líderes populistas como Trump se dirigen directamente, a través de las nuevas tecnologías y de manera personalizada al conjunto del electorado. Así los populismos consiguen dirigirse a sus partidarios sin depender estrictamente del "aparato", los cuadros y "militantes" de los poderosos partidos "leninistas" de otros tiempos. De forma similar se están desarrollando nuevas prácticas y estrategias políticas tanto en las elecciones (por ejemplo, el uso de Cambridge Analytica por Trump) como en la comunicación de las decisiones (por ejemplo, el uso de fake news en un marco de una asumida postverdad).

Las revoluciones tipo "Octubre" eran pensadas como un cambio total entre dos órdenes políticos, sociales, económicos, ideológicos e incluso culturales. Eran significativas las apelaciones al "hombre nuevo" y a la radicalidad de la contraposición antes-después. La revolución era un momento de excepción que rompía totalmente la continuidad entre pasado y futuro. En cambio, y a pesar de cierta retórica, los movimientos populistas actuales asumen que el cambio en absoluto será total, que habrá una inevitable continuidad y que las metamorfosis radicales (en la línea del "hombre nuevo") se manifestarán solamente a largo plazo.

Las revoluciones eran imaginadas como rupturas puntuales que lo cambiaban todo en un lapso corto de tiempo, luego del cual la historia volvería a tranquilizarse y los cambios se limitarían a consolidarse. Mientras los populistas actuales sueñan con extender en el tiempo las transformaciones en una cierta tensión

B CLIVATGE, número 8

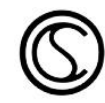


permanente que se niega a "cerrar" demasiado pronto el proceso de cambio y de consolidación del nuevo sistema.

Ciertamente, también en el modelo revolucionario "Octubre 1917" podían darse elementos populistas, pero éstos se pensaban muy concentrados en el tiempo. En cambio, en el populismo "del desconcierto" los cambios "revolucionarios" se imaginan más extendidos en el tiempo, incidiendo en la sociedad a largo plazo y como "una gota malaya" lenta, pero que termina dominando cualquier resistencia. Como vemos, en el fondo, la comparativa entre los revolucionarios clásicos y los populistas contemporáneos no es una cuestión simplemente de mayor o menor ambición.

\section{Aprovechar la oportunidad política de la crisis post2007 y del desconcierto}

Otra característica que comparten hoy los populismos de izquierda y de derecha es que han identificado la situación de larga crisis posterior a los cracs económicos del 2007-2009 como una situación propicia para llevar a cabo los cambios que desean. Han percibido -mucho más agudamente que los partidos tradicionalesel profundo descontento de la población y por tanto la mejor oportunidad en décadas para grandes cambios políticos. Al menos desde inicios de los 1990 con la caída de la URSS y la evolución del Partido Comunista Chino bajo Deng Xiaoping, no se había abierto una ventana de oportunidad tan clara y generalizada para nuevos partidos, nuevas élites y nuevos proyectos político-sociales.

Seguramente la diversidad ideológica entre los populismos hará que sus consecuencias se muevan en direcciones distintas y no en

B Clivatge, número 8

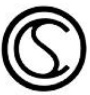


una única. Ahora bien, ello puede incrementar su impacto sobre la historia, en lugar de reducirlo. En cierto sentido, las "políticas del desconcierto" y los populismos dentro de ellas, han abierto una especie de "tiempo revolucionario" donde se está luchando denodadamente por definir el que será el marco político-social hegemónico en los próximos años.

Sin duda, se definirá tanto dentro de los distintos Estados-nación como en la gobernanza internacional que sustituirá al llamado "Consenso de Washington" (Williamson). Pues debe dar respuesta a la todavía abierta Gran Recesión, a las dolorosas políticas de austeridad y al galopante crecimiento de la desigualdad (en récord histórico desde que tenemos datos fiables, según Piketty). Debe enfrentar también a las consecuencias de la cuarta revolución digital, robótica y de inteligencia artificial, que incluye como gran reto la inevitable reducción en el trabajo masivo (Rifkin, 1995).

Todo ello coincide además con cambios geopolíticos significativos como el ascenso de la China como gran potencia mundial, los esfuerzos de Rusia y Turquía por volver ejercer influencia políticomilitar global y el sorprendente repliegue aislacionista de los Estados Unidos. En todo caso, éste parece focalizarse el 2020 en un pequeño grupo de aliados fiables (como el Israel de Benjamín Netanyahu y el Reino Unido de Boris Johnson) y dispuesto a distanciarse de la Unión Europea (que cada vez percibe más como competidora), México e incluso Canadá.

B CLIVATGE, número 8

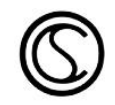




\section{Dilemas del espectro populista: agenda oculta, límite constituyente y choque entre poderes}

Como todo proceso complejo y relativamente nuevo (pues rompe con muchas características que anteriormente lo anticipaban), el populismo desorienta e incluso genera una profunda desconfianza. Hemos expuesto la complejidad ideológica y social de los populismos. Distinguirlos en los dos polos tradicionales de izquierda y derecha tan sólo es una necesidad comunicativa, para no bloquear el avance del discurso. De hecho, no es labor de este artículo clasificar y definir detalladamente los distintos tipos de populismos hoy existentes, pero señalaremos algunos de los principales dilemas que se manifiestan en los populismos "del desconcierto".

La mayoría de los movimientos populistas en los años treinta afirmaban respetar los valores democráticos, la voluntad popular y los derechos civiles y humanos. Hoy, sin embargo, preocupa generalizadamente, y este es uno de los dilemas de los populistas actuales, que aquellos valores no sean una característica permanente y que -en el futuro- puedan derivar en actitudes inequívocamente totalitarias.

Aún más, cabe preguntarse si algunos populismos tienen algún tipo de agenda de tipo totalitario mantenida en secreto y no publicitada. Si existe esa agenda oculta, no sólo cabe preguntarse qué están dispuestos a mantener de los equilibrios institucionales liberales y qué aspectos de la democracia participativa y del gobierno popular aspiran a eliminar o a degradar. ¿Cuáles garantías civiles hasta ahora respetadas en las democracias avanzadas serían

B Clivatge, número 8

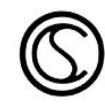


prescindibles y negociables a la baja? ¿Qué valores de libertad pueden ser vulnerados para garantizar un orden político estricto, otros valores securitarios o liderazgos populistas fuertes? ¿Cuáles derechos humanos son innegociables para ellos y cuáles pueden ser transaccionados o eliminados?

No cabe duda que estas cuestiones dilemáticas plantean duda a muchos de los votantes populistas, que lo ven como una opción legítima e incluso necesaria, pero que temen que puedan repetirse nefastos acontecimientos no tan lejanos. Pero hay muchas más que también presentan dudas razonables y angustian a la gente y a los analistas políticos.

También es muy relevante preguntarse, ¿qué límites contemplan los populismos para sus propias acciones críticas, desgastadoras y destituyentes del establishment político-institucional? Como hemos visto, prácticamente todos los populismos actuales consideran necesario abrir un proceso y poder constituyentes o -al menos- llevar a cabo prácticas desafiadoras de las élites e instituciones vigentes que fuercen su rápida renovación. ¿Hasta que punto cada uno de ellos está dispuesto a desestabilizar al Estado y a la gobernanza actual, a poner en peligro la necesaria "seguridad jurídica" y a imponer la agenda de las mayorías sociales por encima de las minorías?

Todo poder constituyente en algún aspecto tiene directas consecuencias destituyentes o desconstituyentes. ¿Hasta qué punto los beneficios obtenidos en cada caso superan a los peligros, riesgos e inconvenientes asumidos? Al respecto Hans Kelsen avisaba que toda democracia sin control no puede ser duradera ni

B CLIVATGE, número 8

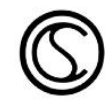


estable. Hoy tenemos complejos ejemplos que reconfiguran la relación entre el poder judicial y los poderes legislativoparlamentario y ejecutivo.

Boris Johnson propuso cerrar por cinco semanas el parlamento británico en el momento álgido de la negociación de la salida del Reino Unido de la Unión Europea. Su intento fue bloqueado por la acción paralela del propio parlamento y del poder judiciario. Donald Trump ha planteado distintos "forcejeos" para imponer sus políticas a otros poderes federales, por ejemplo, presionando a jueces para que aceptaran sus propuestas de restricción de entrada en los Estados Unidos de ciudadanos de ciertos países mirados con desconfianza por su presidencia. También llegó a cerrar la administración federal no vital como parte de su presión para que el Congreso aprobara los presupuestos extraordinarios que pedía para ampliar el muro con México.

En España y Cataluña, pero también en Brasil, se han invocado por parte de algunas instancias judiciales o electorales acciones pocos habituales y que amenazan romper la tradicional división de poderes. Así se ha llevado a destituir, a evitar la elección o a inhabilitar a presidentes y altos cargos de la Generalitat catalana, incluso poniendo en peligro los derechos civiles de los afectados. En Brasil son muy conocidos y debatidos los complejos procesos de destitución y encausamiento de respectivamente los presidentes Dilma Russeff e Inácio Lula da Silva, invocándose en algún caso conceptos -que podemos calificar de "inseparablemente constituyentes y destituyentes"- de por ejemplo "mutación constitucional".
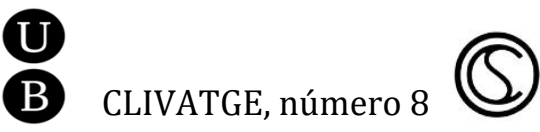
Si se rompe el equilibrio y separación de poderes de Montesquieu, fácilmente uno de ellos o alguna instancia institucional se impone y adquiere características totalitarias. Por si sólo, puede ejercer un poder constituyente (ya no meramente constituido) y evitar la subordinación democrática a la soberanía popular. En términos de Hobbes, esa persona, asamblea, instancia o poder se convierte en lo que Hobbes definía como "el Soberano" efectivo, es decir el poder último de todo el sistema político y no condicionado en el fondo por ningún otro. Eso es lo que más tarde (Arendt, 1974) se llamó totalitarismo, avisando que no surge tan solo de la ignorancia o el lavado de cerebro, sino que tiene causas más profundas en la condición humana, que puede rebrotar con facilidad.

Procesos y mecanismos similares están apareciendo en muchos países. ¿Se trata de un fenómeno momentáneo que la propia dinámica política situará en su justo punto o -por el contrario- irán a más, dislocando las "políticas del desconcierto"? ¿Son más bien reacciones puntuales, excesivas, demagógicas, muy limitadas y espectacularizadas que no tienen el impacto real que parecen tener? Su capacidad de inquietar a través de los massmedia a mucha gente ies su principal efecto o tan solo la punta de iceberg? ¿Muestran una tendencia de la "nueva política" y de las posibilidades tecnológicas digitales que han venido a quedarse y lo pueden cambiar todo?

No es posible aquí profundizar en los mencionados ejemplos, pero sin duda muestran el enorme impacto alcanzado por las "políticas del desconcierto" y los movimientos populistas. La desorientación y preocupación de gran parte de la población también se contagia

B CLIVATGE, número 8

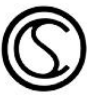


en cuestiones de este tipo a muchos expertos politólogos. Son dilemas no sólo del populismo, sino también de las "políticas del desconcierto", que continúan vigentes al inicio de la tercera década del siglo XXI.

\section{¿Horizontalizar o verticalizar la política? ¿Más pluralismo o menos?}

Como vemos es acuciante resolver los complejos dilemas que plantean los populismos, si bien hay que reconocer que también afectan a los demás agentes políticos en las actuales caóticas "políticas del desconcierto". Pero los populismos -incluso más allá de sus diferencias ideológicas- han tendido a presentarse como movimientos que tienden a horizontalizar y dar pluralidad a la anquilosada vida política tradicional. Una vez más, el problema es hasta qué punto eso es cierto.

Pues -como hemos apuntado- suelen incorporar nuevas capas sociales que se habían apartado de la política. Ahora bien, es preocupante que tiendan a estructurar sus movimientos de forma más informal y con un liderazgo fuerte. Además éste se comunica sin intermediarios directamente con los votantes y recupera la vieja dinámica verticalista: uno activo proyectándose sobre muchos pasivos. Ciertamente se han dado casos -en todos los partidos y no sólo en los populistas- en qué el líder "desconecta" de "su" red social a cualquier interlocutor no obediente. Si bien en cambio, lo bombardea con mensajes adecuadamente "personalizados" de acuerdo con los perfiles que son adquiridos en el mercado, a veces fraudulentamente.

B CLIVATGE, número 8

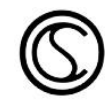


Esos mecanismos que permiten las nuevas tecnologías digitales pueden empoderar y organizar a la gente, pero también subordinarla y convertirla en "clientes" políticos de líderes con pocos escrúpulos (el "ciberleviatán" que temen los liberales Lassalle \& Krause (2019)). Por tanto, fácilmente pueden provocar la verticalización carismática de la política que no su horizontalización democrática. Frente a esas nuevas relaciones directas entre el "líder" y la "masa" pueden tener efectos negativos que hagan añorar los contrapesos liberales y las moderaciones tradicionales como la mediación de los partidos, de los periódicos y medios audiovisuales serios, de las academias y universidades, de los think tanks libres o relativamente autónomos, etc.

Eliminar, reducir o invisibilizar drásticamente esas mediaciones se ha convertido en un importante dilema que se está dirimiendo ahora mismo. No sabemos si agiliza y horizontaliza la política, o provoca todo lo contrario. Pero está claro que las nuevas tecnologías digitales están abriendo ahora mismo posibilidades en esa dirección, completamente impensables hace unos pocos años. Suponiendo que los populismos del desconcierto consigan transformar profundamente el sistema político vigente hasta ahora, ¿introducirán mayor pluralidad y democracia en el sistema o las reducirán peligrosamente? ¿Permitirán que las oligarquías económicas (que han salido muy reforzadas de la crisis2007-2009) puedan gobernar y ejercer directamente el poder político como intenta Donald Trump? ¿Podrán prescindir de una clase política profesional que actuaba como mediadora o podrán realizar de forma mucho más directa su propia agenda política particular? ¿Se

B CLIVATGE, número 8

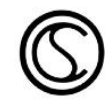


lo facilitarán las nuevas tecnologías digitales, llevando la política a nuevos clientelismos y liderazgos carismáticos?

Como hemos apuntado, quizás ello no adquirirá la forma de los fascismos y totalitarismos de 1930, pues hoy son posibles otras soluciones político-tecnológicas. Significativamente en el aceleracionismo anarcocapitalista radical ya hay quien piensa que los presidentes y jefes de Estado deben actuar y ser considerados como una especie de CEO o Chief Executive Officer que gobierna populistamente las masas o a través de una reducida cantidad de Stakeholders sociales.

Pero en todo caso la "nueva política", surgida tras "el desconcierto" y los populismos, puede tener peligros tan importantes o más que las viejas políticas que creíamos superadas para siempre. Muchos analistas (por ejemplo, Fassin, 2017; Villacañas, 2015) temen que los populismos, después de un efímero éxito y aumento del pluralismo durante lo que llamamos "políticas del desconcierto", acabarán teniendo un impacto mayoritario que reforzará el establishment neoliberal e incluso reducirá significativamente el pluralismo político. Villacañas (2015: 99) ve una correlación estricta entre la persistencia y radicalización del neoliberalismo y del populismo, ambos se retroalimentarían decisivamente.

Evidentemente otros estudiosos (Mouffe, 2018; Mouffe y Errejón, 2015) son mucho más optimistas en las posibilidades de un populismo de izquierda triunfante, precisamente porque facilita la alianza con otros movimientos emancipatorios como el feminismo, el ecologismo y la reivindicación de los subalternizados. También desde la izquierda, Carlos Fernández Liria (2016) o José Luis

B CLIVATGE, número 8

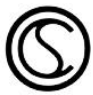


Villacañas (2015) adoptan una postura intermedia donde los populismos de izquierda ofrecerían una oportunidad histórica que acabaría reforzando las opciones del republicanismo más clásico en su lucha en contra del neoliberalismo. Por eso Fernández Liria elogia la capacidad de la coalición española Podemos para convencer a los indignados del $15 \mathrm{M}$ para que asaltaran las instituciones en lugar de mantenerse en una actitud meramente resentida.

Por otra parte, el malogrado Mark Fisher (2009) destacó que el neoliberalismo se había impuesto por encima de cualquier oposición efectiva, hasta el punto que hoy puede prescindir de cualquier legitimación política. Por tanto, parece haberse garantizado la pervivencia sin tener que seducir e incluso sin ofrecer demasiadas contrapartidas a la sociedad. El argumento básico sería del tipo o el neoliberalismo o el caos.

\section{Conclusión: ¿el populismo es más antiliberal y poco cooperativo que antidemocrático?}

Ciertamente los populismos dicen respetar el principio democrático del mandato popular e insisten en ello destacando sus tasas de voto. Pero también se muestran muchísimo más explícitamente críticos con los mecanismos liberales de frenos y balanzas, pues dificultan sus políticas a la vez constituyentes y destituyentes. Ello es especialmente sorprendente en populismos de derecha que como el húngaro de Víctor Orbán que defienden la ortodoxia neoliberal en cuestiones económicas, pero se manifiestan explícitamente "iliberales" en el desmontaje de los

B CLIVATGE, número 8

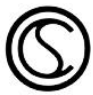


contrapesos entre poderes. Aquí optan por instituir políticas autoritarias que ponen en peligro los derechos civiles básicos y la separación de poderes. Incluso no dudan en aliarse con movimientos claramente de ultraderecha para llevar a cabo políticas destituyentes de los mecanismos clásicos liberales.

Se pueden constatar esas tendencias en la evolución de Orbán en la presidencia húngara a partir del 2010 incluso radicalizadas desde el 2014 cuando definió el régimen que propugnaba como "democracia iliberal". Una vez más, se usa un éxito electoral y una popularidad indiscutibles como un mandato democrático, desde el cual controlar la práctica totalidad de los mecanismos estatales en virtud de un "autoritarismo electo". Así se podrían eliminar incluso las libertades de expresión y de prensa.

De forma parecida, el presidente de Polonia Jarosław Kaczynski ataca la división de poderes sometiendo al tribunal supremo y al judiciario en general a las directrices de su ejecutivo. Paralelamente el presidente de las Filipinas Rodrigo Duterte (que orgullosamente ostenta el alias de "Harry" por el personaje hollywodiense de "Harry el Sucio") ha impuesto una especie de guerra "sucia" en contra de las drogas. Está permitiendo por ejemplo que la policia dispare a matar al mínimo problema, provocando un balance de muertes violentas de entre $4.500 \mathrm{y}$ 12.000 .

También el exministro italiano de interior Matteo Salvini impuso una política de cierre de los puertos italianos a los refugiados, negando las normas de ayuda marítima y de derechos humanos. Incluso mantuvo tales políticas en contra de algunas sentencias

B CLIVATGE, número 8

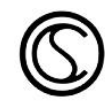


judiciales y por tanto conculcando la separación de poderes. Finalmente, y ante la imposibilidad de ser exhaustivos, el presidente de Turquía, Recep Tayyip Erdogan, instrumentalizó un sospechoso intento de golpe de estado el 2016 para imponer su autoritarismo en el conjunto de los mecanismos estatales, recordar drásticamente los derechos civiles y perseguir a la oposición, disidentes y el pueblo kurdo.

Sorprende que, a pesar del peligro para las democracias de calidad y alto nivel de esas políticas en principio básicamente iliberales, en muchos casos continua la popularidad y el voto en favor de los líderes que las llevan a cabo. Inquieta el apoyo que continúa dando una parte significativa de los ciudadanos a esas agresivas políticas destituyentes de las instituciones liberales y democráticas. Probablemente tienen razón Vallespín y Martínez-Bascuñán (2017: 146) en que ese apoyo ciudadano está relacionado con tales contrapesos han adquirido una complejidad, lentitud e ineficacia que la gente las valora como prácticamente irreformables, por lo cual apoya su eliminación o subordinación al líder populista.

En tal caso, creemos que la población no sería absolutamente contraria al equilibrio de poderes ni a los contrapesos institucionales. Los ciudadanos tampoco no serían esclavos manipulados por líderes carismáticos ni por los nuevos mecanismos digitales de control. En muchos casos su aquiescencia sería una respuesta indignada pero también pragmática, calculada, temporal y no gratuita ante la falta de agilidad de las instituciones para resolver los acuciantes retos económicos, sociales y políticos de la actual era del desconcierto.

B CLIVATGE, número 8

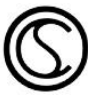


De hecho, y como expone brillantemente Dani Rodrik (2012), la tensión entre las exigencias propias de la democracia, de la turboglobalización internacional y de la soberanía nacional, provoca que muchos gobiernos sacrifiquen la primera para poder mantener las otras dos. Llama a esa "solución" parcial "Camisa de fuerza dorada" que ofrece ejemplos de gran crecimiento -además bastante envidiados- como Singapur o la propia China. Notemos que también aquí se dice respetar el principio democrático del voto popular, mientras que en cambio se menosprecian los contrapesos institucionales de origen liberal que moderan el poder ejecutivo y garantizan los derechos civiles.

Analistas norteamericanos como Rodrik y también Steven Levitsky y Daniel Ziblatt (2018) quizás identifican demasiado democracia con la tradición norteamericana de "checks and balances". Ahora bien, hay que reconocer que tanto ellos como Daron Acemoglu \& James A. Robinson $(2019,2012)$ argumentan bien que la libertad político-social sólo está garantizada en el "estrecho corredor" de equilibrio entre el poder del estado (que incluye a las élites que lo controlan) y de la sociedad civil.

Por eso son muy preocupantes los importantes desgastes que está sufriendo ese estrecho margen de equilibrio por los ataques de líderes y partidos populistas. Pues se están superando "líneas rojas" muy importantes que al final terminan afectando tanto el principio democrático de la voluntad popular como la separación de poderes y los contrapesos institucionales liberales. En última instancia el resultado acaba siendo una clara reducción de la

B CLIVATGE, número 8

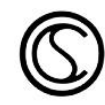


calidad, pluralidad, inclusión, resiliencia y fiabilidad en las democracias avanzadas.

Yascha Mounk (2018), junto con Roberto Stefan Foa, ha analizado distintos mecanismos y signos de "desconsolidación democrática". También Steven Levitsky \& Daniel Ziblatt (2018) ponen de manifiesto tendencias que de mantenerse podrían poner en peligro a democracias consolidadas como las occidentales. Recordemos que Samuel P. Huntington (1994) analizó hasta tres oleadas de países que transitan a la democracia (con sus respectivas contraoleadas antidemocráticas). Ello evidencia que la democracia no es algo que pueda darse por asegurado para siempre sino un ideal y práctica que hay que validar día a día. En ese mismo espíritu, Naomi Klein (2017) avisó de peligrosas y antidemocráticas estrategias en el "capitalismo de la catástrofe" que aprovechan el desconcierto social ante situaciones inesperadas para desmontar derechos sociales adquiridos.

Como hemos visto, hay dilemas abiertos respecto a los populismos del desconcierto. Cómo vayan decantándose marcará mucho el nuevo consenso socio-político futuro que inevitablemente tendrá que surgir como pasó después de la II Guerra Mundial o con el colapso del "socialismo real" por la caída de la URSS y la evolución de la China de Deng. Más adelante hemos apuntado algunos de los retos de las democracias avanzadas que en plenas "políticas del desconcierto" parecen coquetear con peligrosas tendencias de "desconsolidación democrática".

El enigma más inquietante de las actuales "políticas del desconcierto" es la manera como en los próximos años se decidirán

B CLIVATGE, número 8

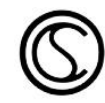


esos dilemas populistas pero también de las democracias avanzadas. Quizás la tarea político-social más importante ahora mismo es conseguir que se resuelvan tales dilemas pacíficamente, con un amplio consenso internacional y dentro del marco democrático. Pues configurará el modelo básico de gobernanza que será hegemónico durante las futuras décadas. Es evidente que la humanidad en conjunto y todos nosotros, nos jugamos mucho en los próximos pocos años.

\section{Bibliografía}

Acemoglu, Daron y Robinson, James A. (2019) The Narrow Corridor: States, Societies, and the Fate of Liberty, Penguin.

Acemoglu, Daron y Robinson, James A. Por qué fracasan los países. Los orígenes del poder, la prosperidad y la pobreza, Barcelona: Deusto, 2012.

Alexandre Walmott tesis doctoral en prensa.

Alfonso Bárcena Gómez, Macrofilosofía del Capitalismo, tesis doctoral en la Universitat de Barcelona, 2015.

Arendt, Hannah (1974) Los orígenes del totalitarismo, Madrid: Taurus.

Arlie Russell Hochschild (2016) A Strangers in Their Own Land: Anger and Mourning [ràbia i dol] on the American Right, The New Press.

Bauman, Zygmunt. (2005) Modernidad líquida, México: FCE. 
BECK, U. La sociedad del riesgo. Hacia una nueva modernidad. Barcelona, Paidós, 2006.

Bernard Stiegler, Dans la disruption: Comment ne pas devenir fou?, Paris, Les Liens qui Libèrent, 2016.

BOLTANSKY, L. y CHIAPELLO, E. (2002) El nuevo espíritu el capitalismo, Madrid: Akal.

Branko Milanovic. Los que tienen y los que no tienen, Alianza, 2012 Chenoweth, Erica \& Stephan, Maria (2012) Why Civil Resistance Works: The Strategic Logic of Nonviolent Conflict, Columbia U.P.

Christophe Guilluy (2015) La France périphérique. Comment on a sacrifié les classes populaires. Flammarion.

Crawford B. Macpherson (1979) La teoría política del individualismo posesivo. De Hobbes a Locke. Barcelona: Fontanella.

Dani Rodrik (2012) La paradoja de la globalización: Democracia y el futuro de la economía mundial, Barcelona: Antoni Bosch Editor.

David Harvey (2007) La breve historia del neoliberalismo, Madrid: Akal.

Douglas Rushkoff Present Shock: When Everything Happens Now, Penguin, 2013.

Éric Sadin (2017) La humanidad aumentada. La administración digital del mundo, Buenos Aires: Caja negra

Fabricio Polido y María Fernanda Repolès (Eds.), Law \& Vulnerability / Direito \& Vulnerabilidade, São Paulo, Almedina Brasil, 2015.

B CLiVATGE, número 8

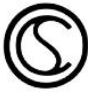


Fassin, Eric (2017) Populisme: le grand ressentiment, París: Textuel. Fernández Liria, Carlos (2016) En defensa del populismo, Madrid: Catarata.

Gómez Villar, Antonio (2018) Ernesto Laclau i Chantal Mouffe: Populisme i hegemonia, Barcelona: Gedisa.

HAN, Byung-Chul, La sociedad del cansancio, Barcelona, Herder, 2012.

Hardt, Michael y Negri, Antonio. Multitud. Guerra y democracia en la era del Imperio, Barcelona, Debate, 2004.

Honneth, Axel. Crítica del agravio moral. Patologías de la sociedad contemporánea, Buenos Aires: FCE, 2009.

Huntington, Samuel P. El choque de civilizaciones y la reconfiguración del orden mundial. Barcelona: Paidós, 2005.

HUNTINGTON, Samuel P., La tercera ola: la democratización a finales del siglo XX, Paidós, 1994

Innerarity, Daniel. (2020) Una teoría de la democracia compleja: Gobernar en el siglo XXI, Galaxia Gutenberg.

Innerarity, Daniel. Política para perplejos, Barcelona: Galaxia Gutenberg, 2018.

Jean-François Lyotard (1984) La condición postmoderna. Informe sobre el saber, Madrid: Teorema.

Jeremy Rifkin (1996) El Fin del trabajo. Nuevas tecnologías contra puestos de trabajo. El nacimiento de una nueva era, Barcelona: Paidós.

Jonathan Hopkin \& Mark Blyth (2018) "The global economics of European populism: growth regimes and party system change in Europe", Cambridge U.P., 
https://www.cambridge.org/core/journals/governmentand-opposition/article/global-economics-of-europeanpopulism-growth-regimes-and-party-system-change-ineurope-the-government-and-oppositionleonard-schapirolecture-2017/32CECBB2EB9F6D707564D5A7944FAB04 José Luis Villacañas (2015) Populismo, Madrid: Huerta Grande. José Ma. Lassalle \& Krause, Enrique (2019) Ciberleviatán: El colapso de la democracia liberal frente a la revolución digital, Barcelona: Arpa.

José Ma. Lassalle (2017) Contra el populismo, Cartografía de un totalitarismo postmoderno, Barcelona: Debate.

Klein, Naomi (2017) No Is Not Enough: Resisting Trump's Shock Politics and Winning the World We Need, Chicago: Haymarket.

Laclau, Ernesto \& Mouffe, Chantal [1985] (2004) Hegemonía y estrategia socialista, Buenos Aires: FCE.

Laclau, Ernesto (2005) La Razón Populista, Buenos Aires: FCE, 2005.

Lipovetsky, Gilles La felicidad paradójica. Ensayo sobre la sociedad del hiperconsumo, Barcelona: Anagrama, 2007.

Manuel Castells: (2006) La Sociedad red. Una visión global, Madrid: Alianza.

Mark Fisher (2009) Realismo capitalista. ¿No hay alternativa?, BsAs: Caja Negra.

Max Horkheimer \& Theodor W. Adorno (1998) Dialéctica de la Ilustración. Fragmentos filosóficos, Madrid: Trotta.

B CLIVATGE, número 8

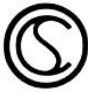


MAYOS, Gonçal, \& BREY, Antoni, (eds.) La sociedad de la ignorancia, Barcelona: Península, 2011.

MAYOS, Gonçal, "Time is money, el hombre de nuestro tiempo" en A lanterna de diógenes: reflexões sobre o homem da pólis contemporânea, Dennys G. Xavier (Coord.); Uberlândia, Laboratório Americano de Estudos Constitucionais Comparado LAECC, 2018a, pp. 403-425.

MAYOS, Gonçal, Homo obsoletus. Precariedad y desempoderamiento en la turboglobalización, Barcelona: Red ediciones, 2016b.

MAYOS, Gonçal, Macrofilosofia della Globalizzazione e del pensiero unico, Barcelona: Red ediciones, 2016a.

MAYOS, Gonçal, Vulnerabilidad, precarización y cambio social. Del capitalismo nofordista al postfordista, en Fabricio Polido y María Fernanda Repolès (Eds.), Law \& Vulnerability / Direito \& Vulnerabilidade, São Paulo, Almedina Brasil, 2015c.

MAYOS, Gonçal. (2018b) "Políticas del desconcierto", https://goncalMayossolsona.blogspot.com/2018/11/politi ca-del-desconcierto.html

MAYOS, Gonçal. (2020) “'Políticas del desconcierto' y redefinición democrática. Una síntesis macrofilosófica" en Ciudadanía y crisis de la democracia liberal en un mundo en transformación, Joan Lara Amat (coord.), Lima: Oficina Nacional de Procesos Electorales (ONPE), 2020.

Mayos, Gonçal. "Cognitariado es precariado. El cambio en la sociedad del conocimiento turboglobalizada", Cooperación y cambio social en el siglo XXI. Eds. Gonzalo de Castro y Begoña Romá. Barcelona: Intervida, 2013c, págs. 143-157.

B ClivatGE, número 8

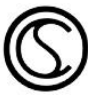


McLuhan, M. y Powers, B.R. (1989). The Global village. Transformations in world life and

Mouffe, Chantal \& Errejón, Íñigo (2015) Construir pueblo. Hegemonía y radicalización de la democracia. Barcelona: Icaria.

Mouffe, Chantal (2018) For a Left Populism. London: Verso.

Mouffe, Chantal En torno a lo político, Buenos aires: FCE, 2007.

Nancy FRASER \& Rahel JAEGGI, Capitalism. A Conversation in Critical Theory), Oxford, Blackwell's UK. 2018.

Paul Mason (2016), Postcapitalismo. Hacia un nuevo futuro, Barcelona: Paidós.

Piketty, Thomas (2014) El capital al segle XXI, Barcelona: RBA, (2013).

Piketty, Thomas (2019) Capitalisme i ideologia, Barcelona: Grup62. Richard Sennett (2000) La Corrosión del carácter. Las consecuencias personales del trabajo en el nuevo capitalismo, Barcelona: Anagrama.

Rivero, Ángel, Zarzalejos, Javier y Palacio, Jorge del (2017) Geografía del Populismo. Un viaje por el universo del populismo desde sus orígenes hasta Trump. Madrid: Tecnos.

Rodrik, Dani (2018) "Populism and the economics of globalization" en Journal of International Business Policy volume 1, pp. 1233.

Ronald Inglehart (2001) Modernización y posmodernización. El cambio cultural, económico y político en 43 sociedades, Madrid: Centro de Investigaciones Sociológicas \& Siglo XXI.

B CLIVATGE, número 8

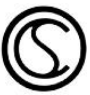


Ronald Inglehart (2018) Cultural Evolution: People's Motivations are Changing, and Reshaping the World, Cambridge U.P.

Sharun Mukand \& Dani Rodrik (2015) "The Political Economy of Liberal Democracy" en NBER Working Paper No. 21540, Sept. 2015, https://www.nber.org/papers/w21540

Steven Levitsky \& Daniel Ziblatt (2018) How Democracies Die: What History Tells Us About Our Future. Penguin Books.

Vallespín, Fernando \& Martínez-Bascuñán, Máriam (2017) Populismos, Madrid: Alianza.

Yascha Mounk (2018)The People vs. Democracy. Why Our Freedom Is in Danger and How to Save It. Harvard U.P.

Zygmunt Bauman / Keith Tester La ambivalencia de la modernidad y otras conversaciones, Barcelona, Paidós, 2002.

\footnotetext{
Este texto está protegido por una licencia ReconocimientocreativeCommons 4.0.
(c) déculo, los/as autores/as
Usted es libre decompartir - copiar y redistribuir el material en cualquier medio o formato- y adaptar el
documento - remezclar, transformar y crear a partir del material - para cualquier propósito, incluso
comercialmente, siempre que cumpla la condición de:
Atribución: Usted debe reconocer el crédito de una obra de manera adecuada, proporcionar un enlace a la
licencia, e indicar si se han realizado cambios. Puede hacerlo en cualquier forma razonable, pero no de forma tal
que sugiera que tiene el apoyo del licenciante o lo recibe por el uso que hace.
Resumen de licencia - Texto completo de la licencia
}

B CLIVATGE, número 8

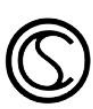

